LAWRENCE LIVERMORE NAT IO N A L LABORATORY

\section{Optical Probes For Continuous Fabry-Perot Velocimetry Inside Materials}

D.R. Goosman, J. Wade, R. Garza, G. Avara, T. Crabtree, A. Rivera, D. Hare, D. Tolar, B. Bratton

August 13, 2004

26th International Congress on High Speed Photography and Photonics

Alexandria, VA, United States

September 19, 2004 through September 24, 2004 
This document was prepared as an account of work sponsored by an agency of the United States Government. Neither the United States Government nor the University of California nor any of their employees, makes any warranty, express or implied, or assumes any legal liability or responsibility for the accuracy, completeness, or usefulness of any information, apparatus, product, or process disclosed, or represents that its use would not infringe privately owned rights. Reference herein to any specific commercial product, process, or service by trade name, trademark, manufacturer, or otherwise, does not necessarily constitute or imply its endorsement, recommendation, or favoring by the United States Government or the University of California. The views and opinions of authors expressed herein do not necessarily state or reflect those of the United States Government or the University of California, and shall not be used for advertising or product endorsement purposes. 


\title{
Optical probes for continuous Fabry-Perot velocimetry inside materials
}

\author{
David Goosman, James Wade, Raul Garza, George Avara*, Thomas Crabtree, Anthony Rivera, \\ David Hare, Danny Tolar, Jr, and Bradford Bratton \\ The authors (*G.A. being retired) are with Lawrence Livermore National Laboratory \\ P.O. Box 808, L-281, Livermore, CA 94550 \\ 925-422-1630, fax 925-422-2382,email - goosman1@1lnl.gov
}

\begin{abstract}
We have used velocimetry for many years at LLNL to measure velocity-time histories of surfaces in dynamic experiments. We have developed and now use special instrumentation to make continuous shock-velocity measurements inside of materials. The goal is to extend the field of velocimetry into a new area of application in shock physics.

At the last Congress we reported the successful use of our new filter system for selectively eliminating most of the nonDoppler-shifted light. We showed one record of a fiber embedded inside an explosive making a continuous detonation velocity-time history. At that time it was difficult to obtain complete records. We have now carried out over 65 inexpensive experiments usually using small cylinders or rectangular blocks of explosives or metals. Most were started by detonating a $25 \mathrm{~mm}$ diam by $25 \mathrm{~mm}$ long cylinder of Comp B explosive to drive a shock into an adjacent material of similar dimensions, using our embedded fiber probes.

In contrast to surface velocimetry, embedded measurements involve detailed hydrodynamic considerations in order to result in a successful record. Calculations have guided us in understanding of various failed and successful experiments. The homogeneity of the explosive, poor contact, the materials used in the cladding and core of the fiber optic probes, and the shock speeds to be covered all greatly affect the success of an experiment.

For example, a poor contact between the optical fiber and its environment causes severe loss of data. Non-symmetric air gaps on one side of the fiber cause 3 dimensional hydrodynamic effects which cause the shock wave in the fiber core to be too steeply angled to reflect light. We have recently developed and successfully used a special probe to usually overcome this limitation.
\end{abstract}

We have custom designed several unique types of fiber-optic probes for specialty applications, using both solid and liquid core materials, to extend the usable shock-velocity range.

Keywords: velocimetry, embedded, fibers, Fabry-Perot

\section{INTRODUCTION}

Velocimetry is used at LLNL to measure the time dependent velocity of surfaces accelerated by various means ${ }^{1}$. Since Fabry-Perot systems can handle more than one frequency of return light, our group has used those systems for the last 19 years. Our manybeam velocimeter system was described briefly at a recent Congress ${ }^{2}$.

Several years ago, the first author was shown records taken at LANL by W. Hemsing ${ }^{3}$ done to measure continuous detonation velocities within explosives. This was accomplished by monitoring the frequency of light reflected from the 
moving crushed fiber end within the explosive. Two such experiments were then carried out at LLNL in 1998. The data made sense, but was frequently obscured by non-Doppler shifted light that was one or two orders of magnitude stronger than the data sought. We therefore devised a filtration system to mostly eliminate the non-shifted light to obtain better records.

Placing optical fibers within explosives to measure continuous detonation velocities can result in large amounts of undesired non-Doppler shifted light scattering from fiber imperfections and connections. We designed and constructed a special filtration system, described in the preceding Congress, based upon angled fiber connections and a Fabry-Perot etalon that reduces this undesired light by a factor of more than 100, thus helping to make possible for us this new field of shock velocimetry inside materials.

\section{EXPERIMENTS WITH SILICA FIBERS}

An embedded fiber experiment with a silica fiber being enveloped by a detonation wave is shown in figure 1.

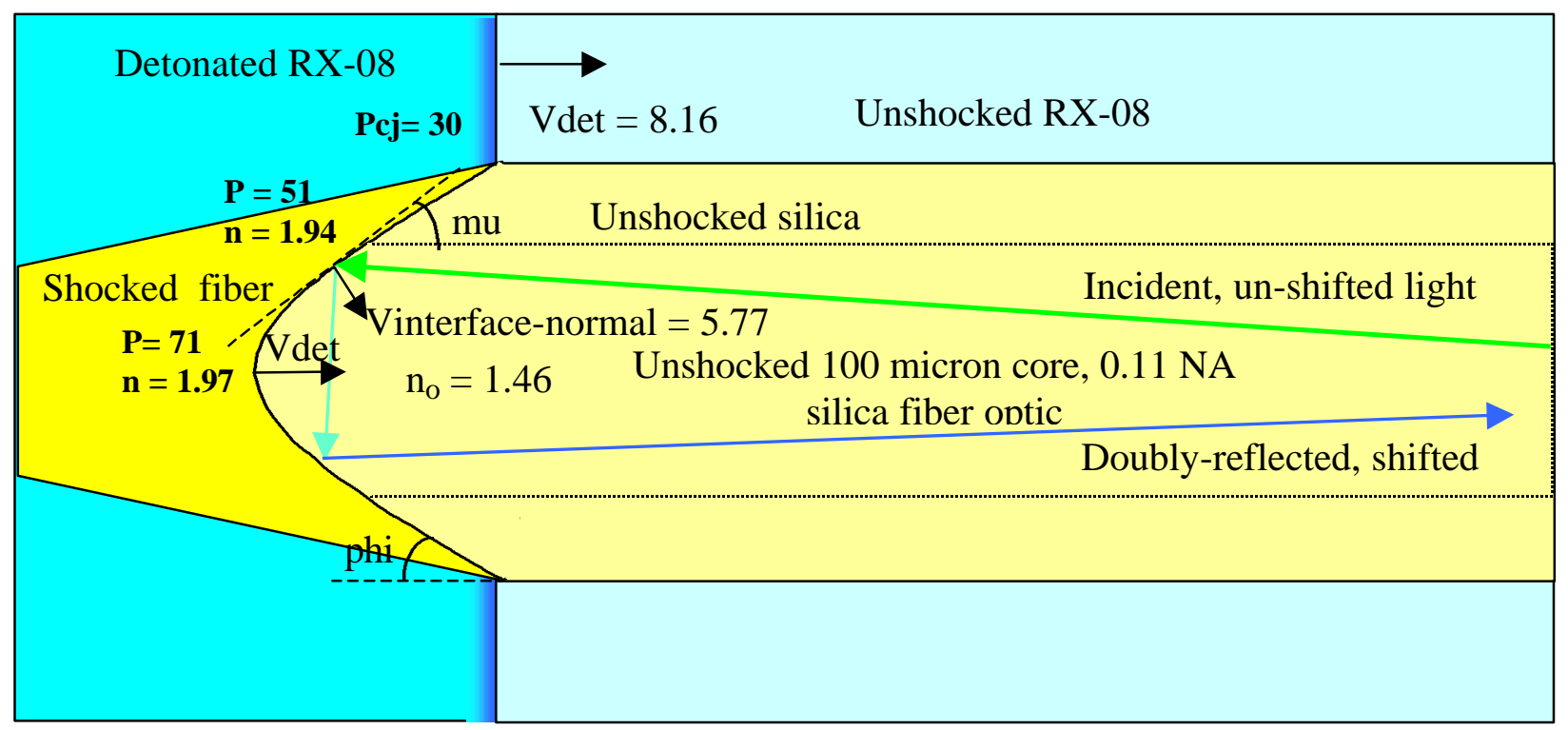

Figure 1. Approximate shape of the end of a crushed fiber in RX-08HD explosive.

Pressures are in GPa, as calculated by Souers ${ }^{4}$, the refractive index is $\mathrm{n}$, and velocities are in mm/usec. The description of this figure, as well as a discussion of various matters relating to the Doppler shift of reflected light were given in the previous Congress 5 .

Our early experiment with bare silica fiber embedded into solid explosives had limited success, due to the presence of air gaps between the fiber and the grooves machined into the explosives. Figures 2 and 3 show the effects of having the fiber to LX-17 annular gap filled with glue.

Here we used $25.4 \mathrm{~mm}$ diameter cylinders of CompB explosive in contact with cylinders of LX-17 explosive each 50 $\mathrm{mm}$ long. The LX-17 cylinders were split in half and grooved to fit the silica fiber. Machined grooves in each half just held the fibers in approximate contact with the LX-17. The epoxy used to glue the silica fiber into place for the experiment of figure 3 was centrifuged and vacuum treated to minimize air bubbles. 


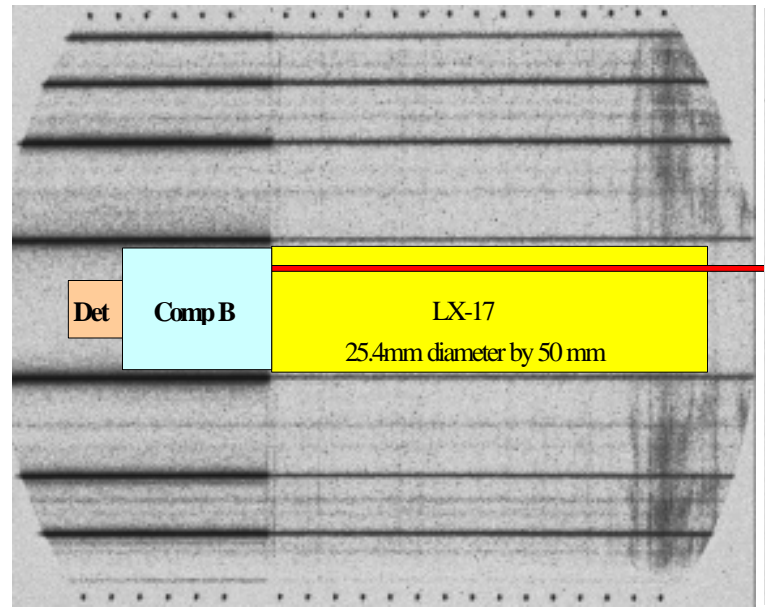

Figure 2. Silica fiber in LX-17 without glue. The time fiducials are $500 \mathrm{nsec}$ apart.

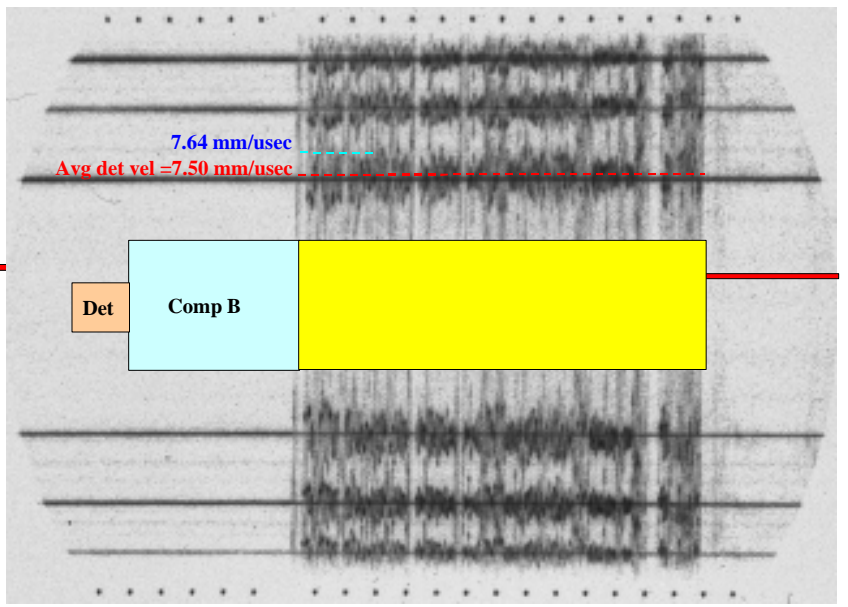

Figure 3. Silica fiber well glued into LX-17.

The rapid oscillations in figure 3 represent only a $1.5 \%$ variation in velocity, since the detonation velocity of 7.50 $\mathrm{mm} /$ usec represents a change of just over 12 orders. The fact that the fringes appear to oscillate about the original baselines is coincidental. The change in baseline intensity at the boundary between CompB explosive and LX-17 in Figure 2 is due to the cessation of non-shifted light from the end of the silica fiber as the shock reaches that point. The white band near the end of the record is probably due to a small air gap from an imperfect glue contact on the fiber.

We believe the fluctations in Fig. 3 are due mostly to the granularity of the LX-17 explosive which is comparable to the fiber diameter. In order to verify this we replaced the LX-17 with TMETN, a liquid explosive. A small polycarbonate barrier with a tiny hole for the fiber was placed halfway into the liquid to study the time for the detonation to equilibrate after the disturbance due to the barrier. A detonator and cylinder of TNT started the shock wave in the TMETN.

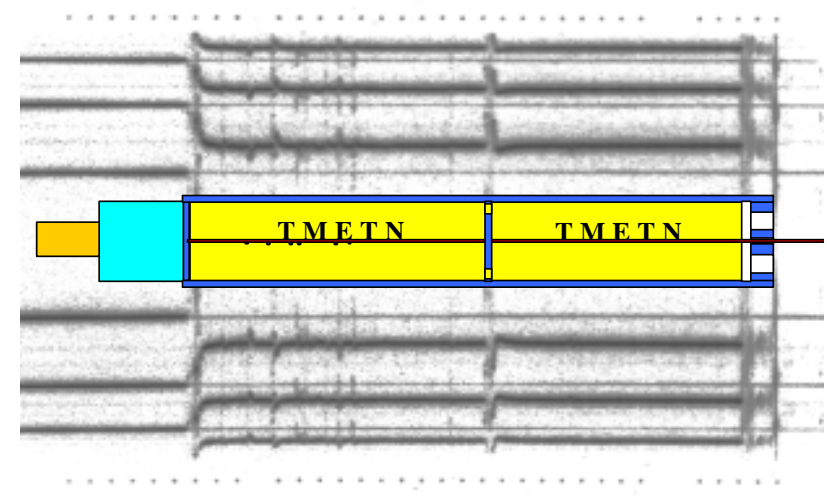

Figure 4. TMETN with 1 ìsec per marker.

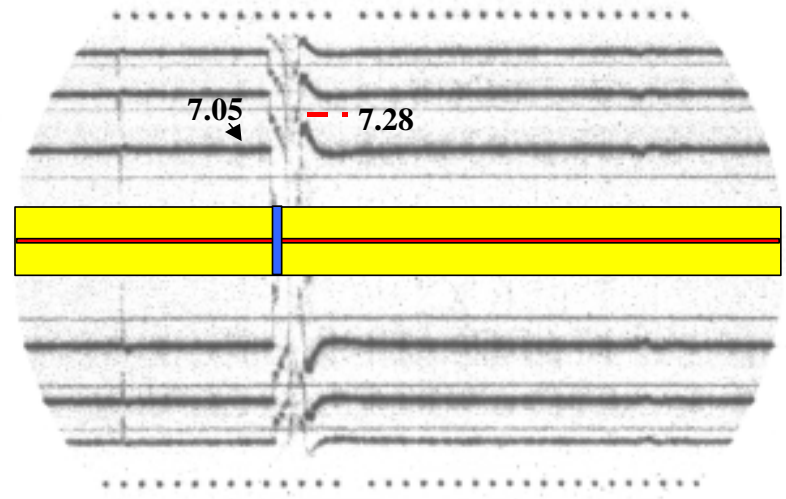

Figure 5. $200 \mathrm{nsec} / \mathrm{mark}$ record near the barrier.

Figure 4 shows the full record on both sides of the barrier. Notice the many brief time intervals on the upstream side of the barrier that show a velocity disturbance, and the almost complete lack of them on the downstream side of the barrier. We believe this is due to friction between the glass fiber and the tiny hole in the barrier inducing charge on the silica fiber during insertion from the right end. This charged glass then attracted dust particles in the air prior to filling with TMETN. The dust particles and possible trapped air bubbles cause a brief hydrodynamic disturbance on the shape of the reflecting interface between the shocked and unshocked core of the silica fiber. The right hand side has almost no diturbances due to the lack of friction during insertion. The velocity of $7.046 \mathrm{~mm} / \mathrm{isec}$ is accurate to about $0.25 \%$. 
Figure 5 shows the expanded time region near the barrier. It takes less than $600 \mathrm{nsec}$ for the record to recover to equilibrium velocity.

Figure 6 is a partial record of a 100-140-170 micron silica fiber glued into a cylindrical hole in a cylinder of 6061-T6 aluminum $25.4 \mathrm{~mm}$ in diameter. After a side rarefaction arrives at about $2.5 \mathrm{isec}$, the record stops.

Another fiber type consisting of SF6 glass is capable of measuring lower shock speeds than fused silica, which has no shock waves with speeds less than about $4.9 \mathrm{~mm} / \mathrm{isec}$. A record of detonation in the liquid explosive nitromethane is with the SF6 fiber shown in Figure 7.

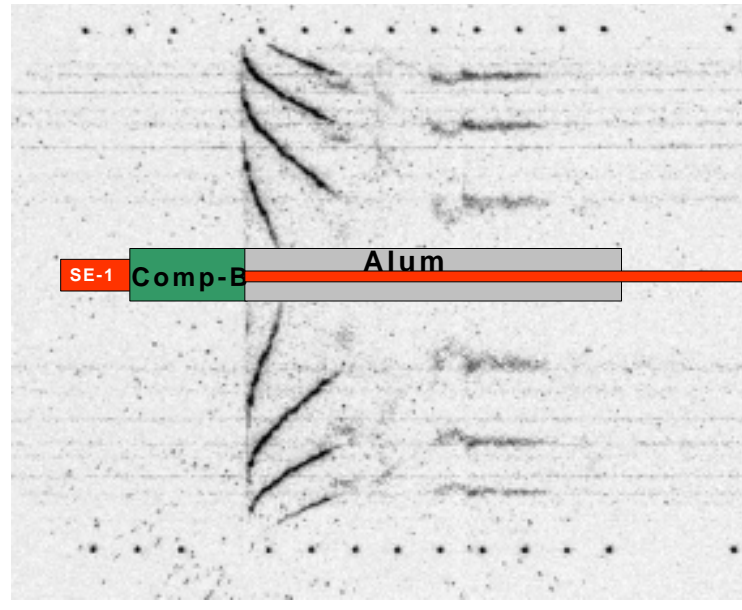

1 microsecond markers

Figure 6. Shock decay in $\mathrm{Al}$ with silica fiber.

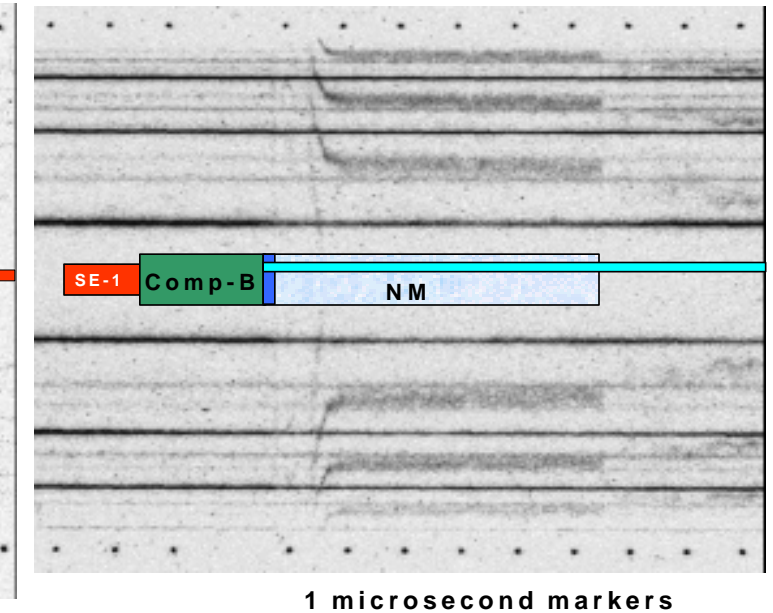

Figure 7. Detonation in nitromethane.

Using silica fibers, we were never able to obtain records longer than about $2.5 \mathrm{isec}$ in aluminum, which starts near 7 $\mathrm{mm} / \mathrm{usec}$ and stops near $6.3 \mathrm{~mm} / \mathrm{usec}$. The nitromethane record in figure 7 takes about 1 microsecond to equilibrate at $6.28 \mathrm{~mm} / \mathrm{usec}$, after traversing layers of acrylic and glue to hold the fibers in place.

After many experiments with silica and SF6 fibers, it was clear that small air gaps between the fiber and a solid driving material surrounding it caused the records to cease. Presumably the shock wave caused by the gap closure causes a 3dimensional hydrodynamic perturbation on the shape of the shocked-unshocked fiber core interface. If this shape is a linear interface at an angle and no longer a cup-shaped interface similar to that in figure 1, then no light from specular reflections off of the shock can return back the fiber, so the record ceases.

Because of this, we decided to try cladding the fiber probes with more material to smooth out the azimuthal inhomogenieties surrounding the fiber, in hopes that this would make the effect of small gaps less harmful. In addition, shocks in fused silica do not exist below shock speeds of about $5 \mathrm{~mm} / \mathrm{isec}$, and we wished to extend the range of velocities for our probes. SF6 glass fibers in principle extend this range somewhat, but these unclad fibers are difficult to handle without breaking.

\section{LIQUID CORE OPTICAL PROBES - CsCl + PTFE}

We searched through shock Hugoniot data for shock speeds, pressures and densities that can be reached by a single shock for a wide variety of materials. For a fiber core material, one needs a transparent material that can support low shock speeds and have an index of refraction high enough to exceed that of a reasonable cladding material. The cladding material also must presumably support low shock speeds to work. This search indicated that PTFE microtubing filled with a $80 \%$ of saturated aqueous solution of $\mathrm{CsCl}$ was an attractive possibility. A $\mathrm{CsCl}$ solution at 7 $\mathrm{M}$ has a density of 1.88 , and we measured the index of refraction at $532 \mathrm{~nm}$ of 1.411 using a refractometer. The PTFE 
cladding index is near 1.35. Hugoniot data extend up to $5.2 \mathrm{~mm} / \mathrm{usec}$ shock speed, where the shocked density is 3.24 . We estimate by a very simple approximation that in this state the index is about 1.72 for $532 \mathrm{~nm}$ light. This would produce a $1 \%$ reflectivity for normal incidence, or about 0.0001 reflectivity for two reflections at 45 degrees.

The index of refraction of PTFE is sufficiently less than that of unshocked $7 \mathrm{M} \mathrm{CsCl}$ solution so that it works very well as an optical fiber. We obtained PTFE tubing of several inside and outside diameters. We have constructed probes nearly $30 \mathrm{~cm}$ long and little attenuation of the light is observed along the length, as evidenced by the intensity of the glow through the translucent cladding. One of our early versions of the liquid $\mathrm{CsCl}$ probe is illustrated in figure 8 . The 0.11 NA silica fiber leading from the laser has diameters of 100, 140 and 170 microns for the core, clad and buffer, respectively. It is optically touching the liquid which has a diameter of 178 microns. . Light enters from the right-hand side.

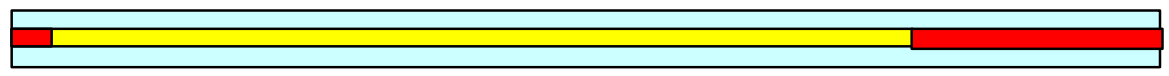

Figure 8. The first version of our CsCl-PTFE shock velocity probe.

The left end is a plug to seal the tubing. The right end is also sealed. It is very important to fill the liquid without air bubbles, and that the liquid-silica fiber iterface is very clean and not scatter light.

\section{DATA WITH THE NEW PROBES}

Two of the first experiments with the new probes are shown in figures 9 and 10, which are records taken in nitromethane, a liquid explosive.

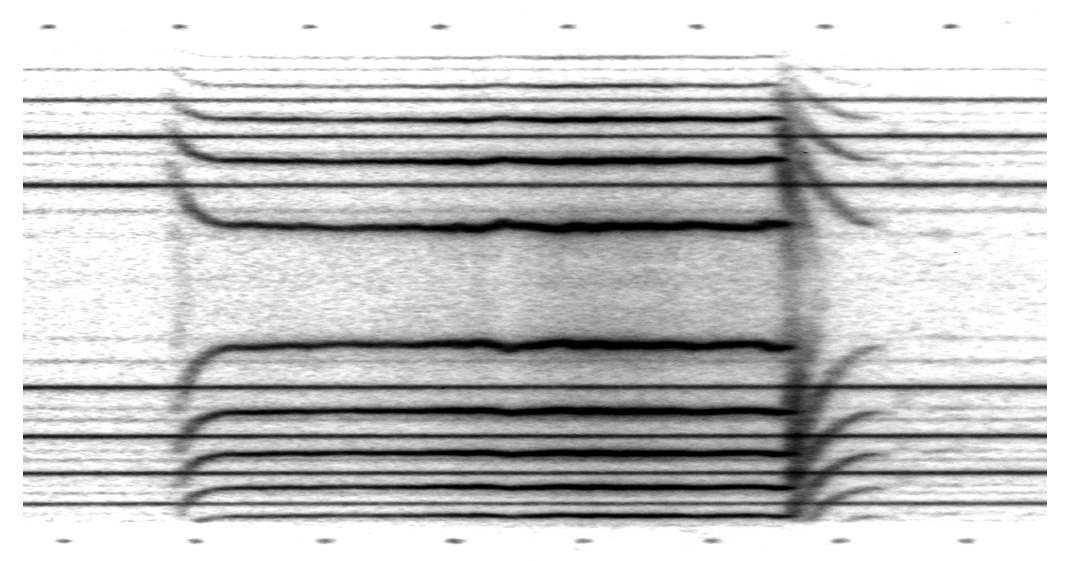

Figure 9. Nitromethane (NM) driven by CompB as recorded with the new CsCl-PTFE probe.

After being overdriven by the CompB, the velocity equilibrates to $6.28 \mathrm{~mm} / \mathrm{usec}$ in considerably less than $1 \mathrm{usec}$, which is the time between markers. Upon reaching the top of the NM liquid, the shock velocity rapidly decreases for another $800 \mathrm{nsec}$ (about $3 \mathrm{~mm}$ ) before the record ceases. This deceleration as the shock leaves the liquid NM is the slowing down of the shock in the $\mathrm{CsCl}$ solution-PTFE probe because there is no mass surrounding the probe anymore. Because the Fabry-Perot interferometer was only a single cavity for this experiment, we can say only that the final velocity after deceleration was either 3.5 or $2.1 \mathrm{~mm} / \mathrm{isec}$, since the velocity per fringe was $1.4 \mathrm{~mm} / \mathrm{issec}$.

We then used the same probe design, except this time we use thinner walled PTFE tubing, with an ID and OD of 0.18 and $0.9 \mathrm{~mm}$, respectively. Figure 10 shows a double-cavity record taken in aluminum driven by CompB with this probe. No glue was used between the aluminum and PTFE 


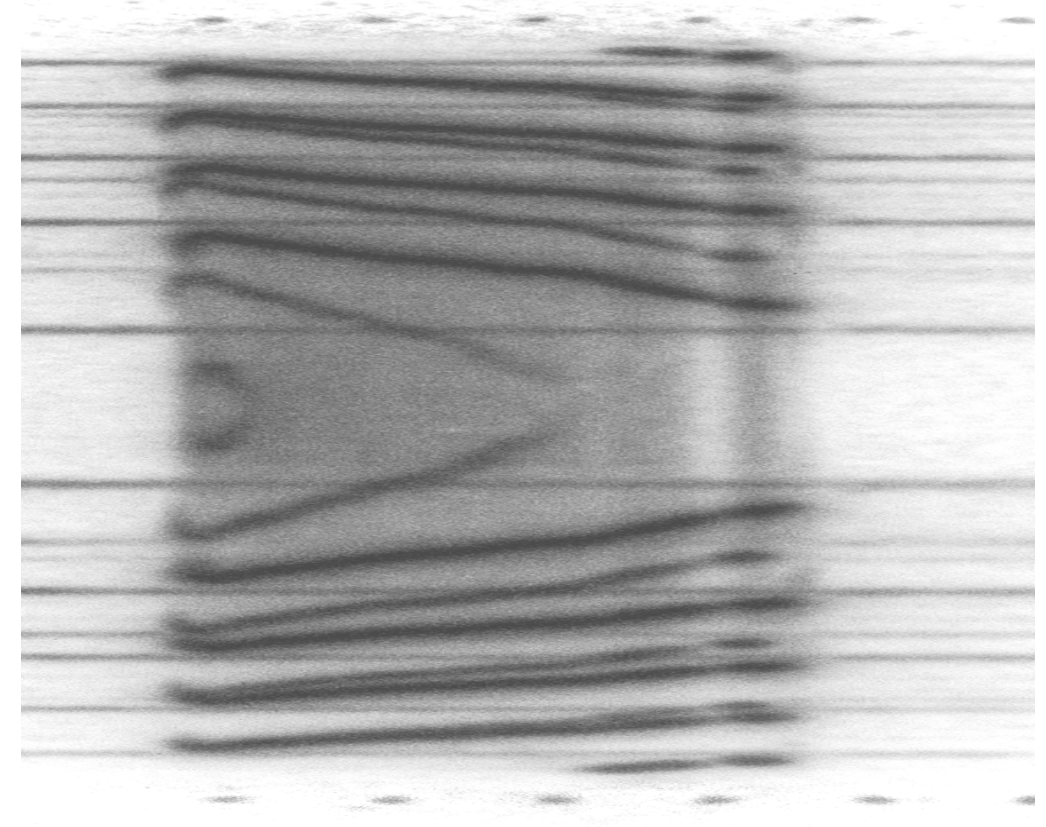

Figure 10. Record taken in $25.4 \mathrm{~mm}$ long $25.4 \mathrm{~mm}$ wide rectangular Aluminum 6061-T6 block. No glue was used.

The time markers are 1 ìsec apart, and the record extends completely to the end of the $25 \mathrm{~mm}$ long block.

Obtaining this record, we though that we had a technique for inserting probes into materials without glue that worked. However, later experiments showed that the technique is not reliable and that a gap filler is necessary to get reproducible results.

The time response of the thicker walled probe was tested by the following experiment to watch a decaying shock in aluminum cross into brass region, where the shock velocity would decrease rapidly. The experiment is shown below.

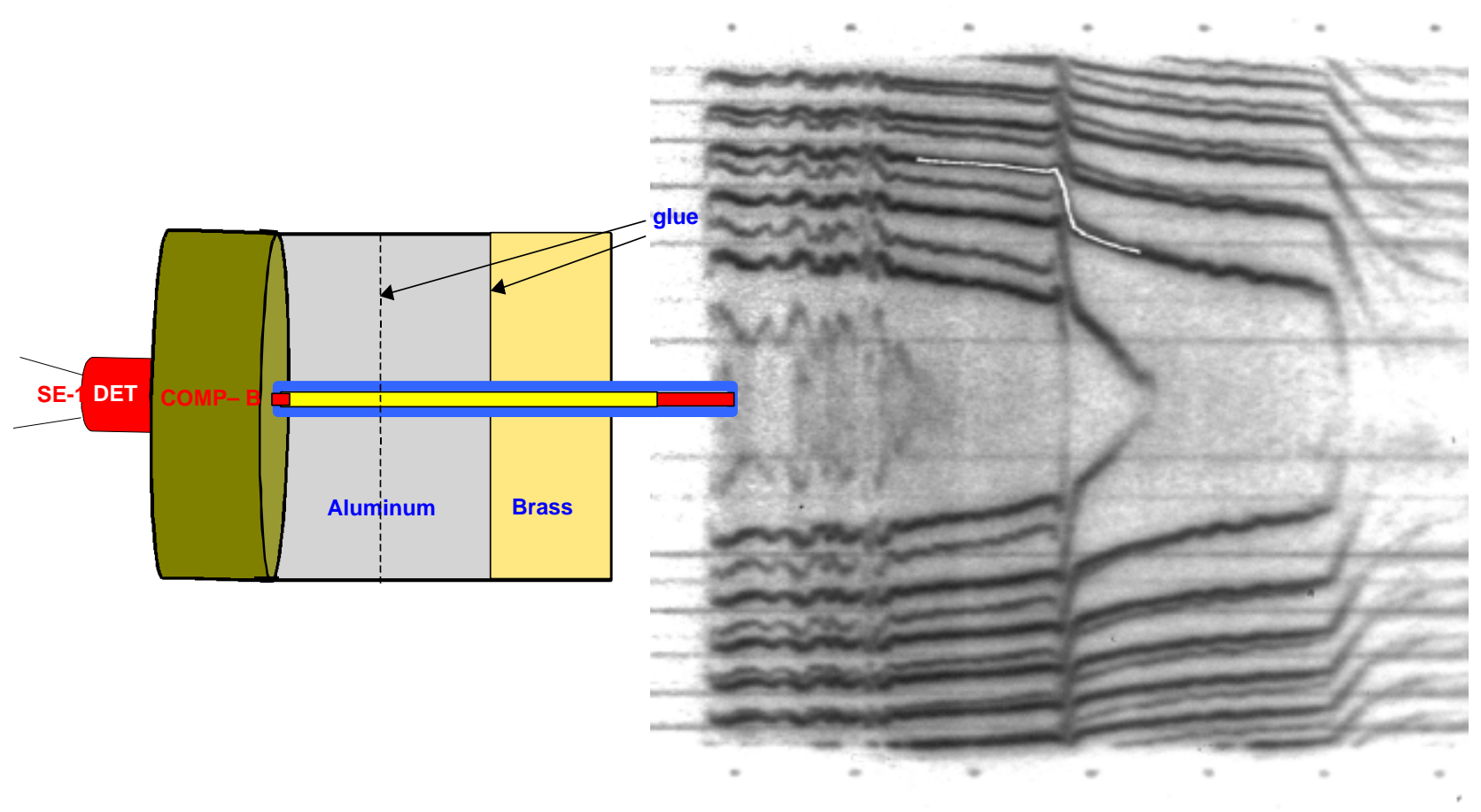

Figure 11 Shock decay in an Aluminum-Brass combination. 


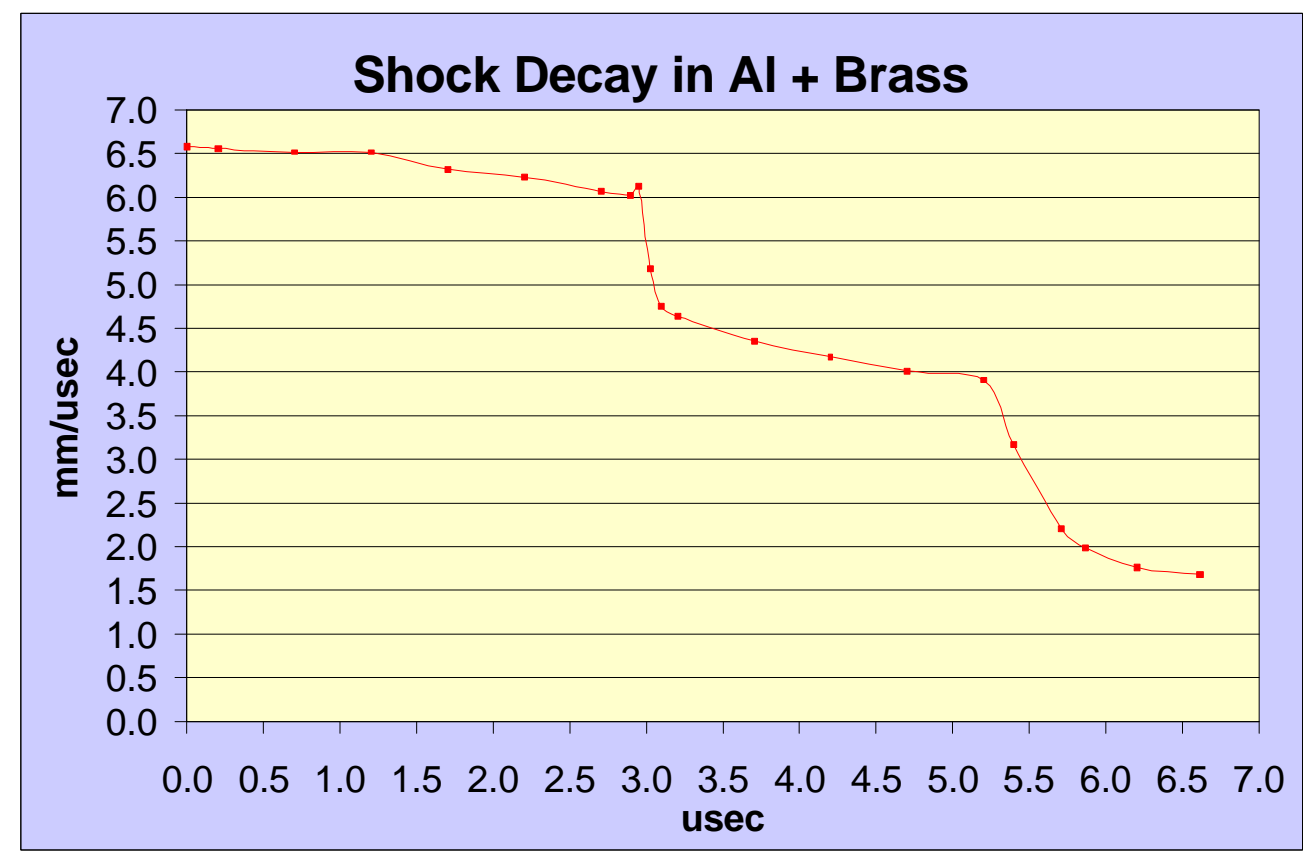

Figure 12. Velocity-time curve for the aluminum-brass experiment.

This experiment consisted of two $1 \mathrm{~cm}$ long blocks of aluminum and a $1 \mathrm{~cm}$ long block of brass, each $25.4 \mathrm{~mm}$ wide. Both interfaces were glued and the PTFE to metal boundary was reasonably filled with glue. However, as evidenced from the record, the first aluminum block $1 \mathrm{~cm}$ long was not well contacted and caused oscillations in the apparent velocity. The second aluminum block and the brass block had good contact and produced smooth records. The double cavity record above shows the transition from aluminum to brass takes about $150 \mathrm{nsec}$ as view by the $1.6 \mathrm{~mm}$ diameter PTFE-CsCl probe. This transition jumps almost exactly one fringe on the record, and is shown by the white line. The velocity changes from 6.00 to $4.7 \mathrm{~mm} / \mathrm{isec}$ through the transition, which included a thin glue layer. A brief increase in the apparent velocity occurs just prior to the drop in velocity. This experiment will be repeated with a better coupling medium between the PTFE and the metals.

The velocity drops rapidly as the shock hits the end of the brass cylinder from $3.89 \mathrm{~mm} / \mathrm{usec}$ to $1.68 \mathrm{~mm} / \mathrm{usec}$. During this transit through the probe which is now surrounded by air, the total measured distance was $3.2 \mathrm{~mm}$. Since the brass particle velocity near Us $=3.9 \mathrm{~mm} / \mathrm{isec}$ is near $0.1 \mathrm{~mm} / \mathrm{isec}$, the shock in the $\mathrm{CsCl}$ outruns the free surface velocity of the brass end. We intend to repeat this experiment with thinner walled PTFE to see if the transistion time decreases. We also need to reverse the order of the brass and aluminum to see what the transition times are when the shock velocity increases across a boundary.

\section{THE MYSTERY FRINGE IN ALUMINUM}

In an attempt to eliminate the oscillations noted above due to incomplete contact between the PTFE and metal, another experiment was constructed with a 40-mm long aluminum rectangular block, $25.4 \mathrm{~mm}$ square. This time the aluminum was held vertically while the hole was filled with glue and then the PTFE probe inserted. The record is shown below. 


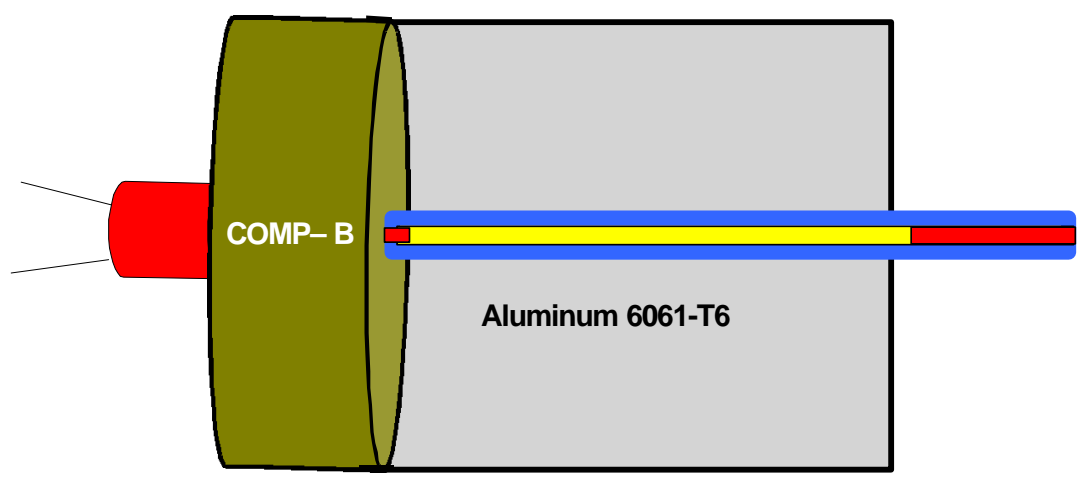

Figure 13. The aluminum experiment with the unexplained new fringe.

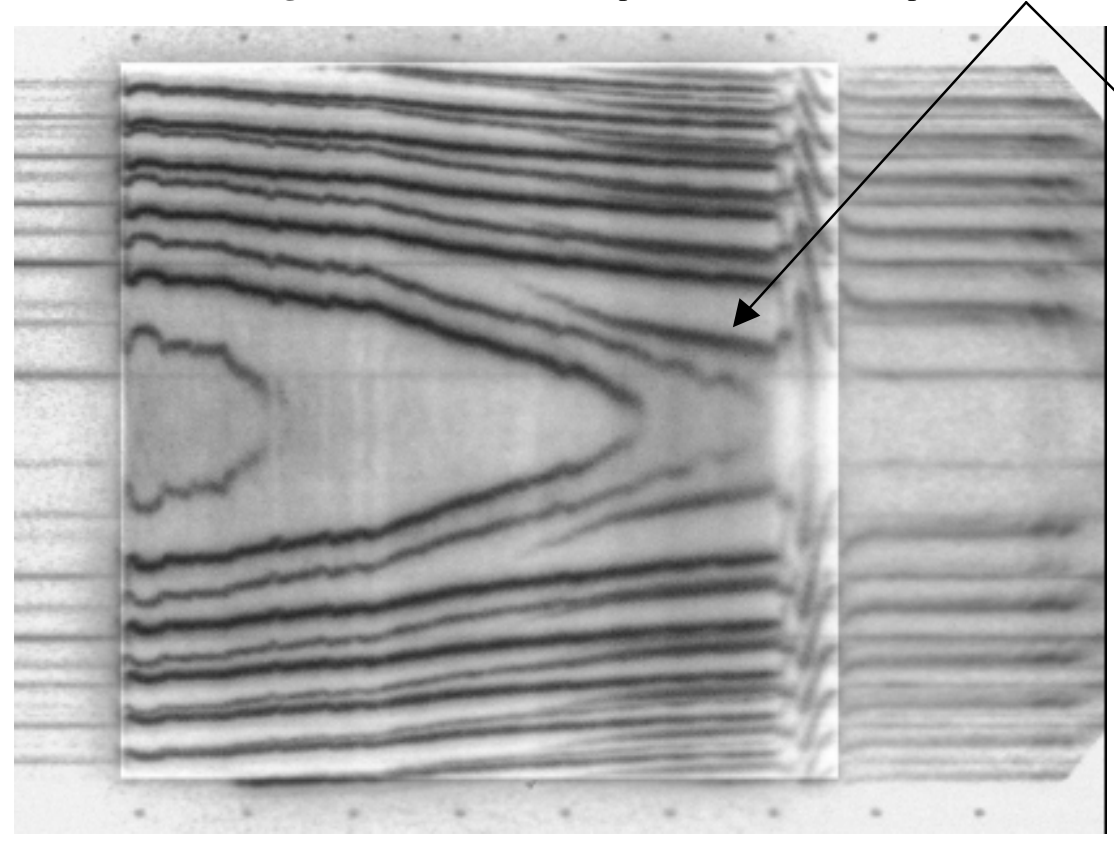

Figure 14. The full aluminum record.

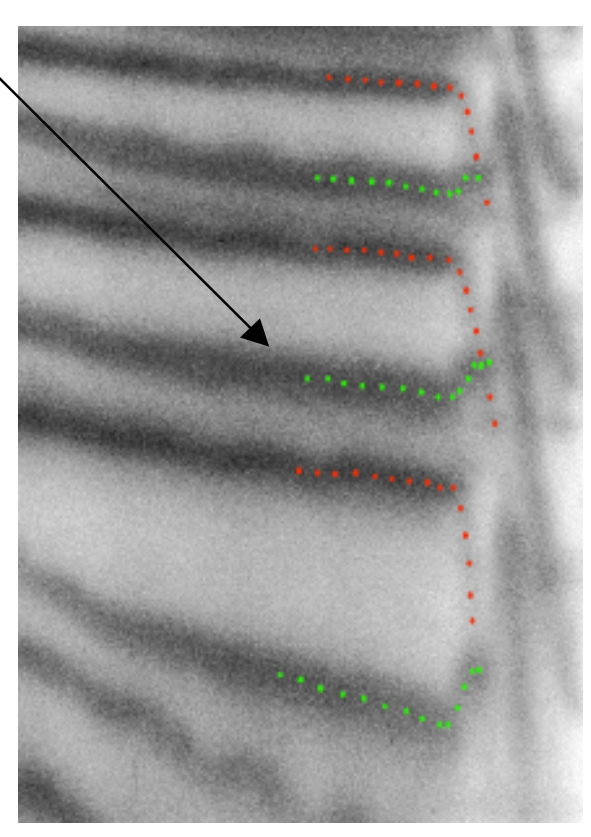

Figure 15. Closeup of figure 14.

The silica plug at the left of figure 13 was about $3 \mathrm{~mm}$ long and the $\mathrm{CsCl}$ solution extended about $2 \mathrm{~mm}$ beyond the end of the aluminum block. Figure 13 does not show two layers of tape and one layer of glue between the CompB explosive and the aluminum block, which have a total thickness of about $0.5 \mathrm{~mm}$.

The rectangular section in figure 14 about 6.9 ìsec long has been reduced in intensity digitally to make the exposure of the entire record more readable, since the record initially was heavily exposed with light This is a double cavity record with a velocity sensitivity of $1.133 \mathrm{~mm} / \mathrm{sec}$ per fringe for the main cavity lines and $0.958 \mathrm{~mm} / \mathrm{usec}$ per fringe for the referee cavity lines. The brightest fringes are main cavity lines and the next brightest are referee lines.. The measured velocity with the probe starts at $6.65 \mathrm{~mm} / \mathrm{isec}$ and ends at $5.38 \mathrm{~mm} / \mathrm{isec}$ as the shock leaves the end of the block. The integrated velocity-time to the end of the block is $36.9 \mathrm{~mm}$. Aluminum has a sound speed of $5.27 \mathrm{~mm} / \mathrm{isec}$, so the record extends almost down to that speed. The closeup in figure 15 shows one main cavity fringe rapidly decelerating at the end of the block, as well as an apparent increase in frequency of a mystery fringe at that time.

The unexpected fringe shows up at 3.66 ìsec after the normal main cavity fringe starts. The referee component of this fringe also shows up clearly enough at one time to almost uniquely determine the absolute frequency. The best double- 
cavity velocity match at 5.16 ìsec between referee and main fringes is $2.01 \mathrm{~mm} / \mathrm{isec}$ for the equivalent velocity of a mirror moving in vacuum that would give the same observed frequency. Another but quite poor match occurs near 7 $\mathrm{mm} / \mathrm{isec}$. These results repeated in another aluminum experiment as well with more clearly defined referee mystery fringes.

The vacuum-equivalent velocity of $2.01 \mathrm{~mm} / \mathrm{isec}$ must be corrected for the time derivative of the optical path ahead of it caused by the motion of the leading shock wave moving at $5.5 \mathrm{~mm} / \mathrm{isec}$ at this time.

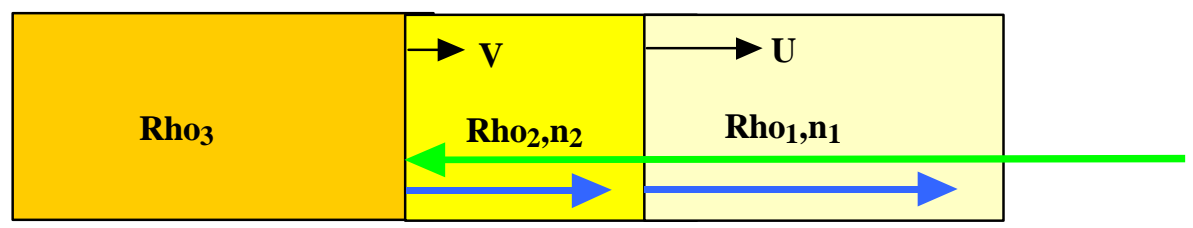

Figure 16. One dimensional model of leading shock $\mathrm{U}$ followed by reflecting boundary with speed $\mathrm{V}$ in $\mathrm{CsCl}$ solution.

Here the frequency shift from the downstream reflection is proportional to $\mathrm{n}_{2} *(\mathrm{~V}-\mathrm{U})+\mathrm{n}_{1} * \mathrm{U}$

If the second reflecting layer is close to the $\mathrm{U}$ shock front, then this result implies an inferred actual velocity $\mathrm{V}_{2}$ of about $2.2 \mathrm{~mm} / \mathrm{isec}$, which is a reasonable value for a particle velocity behind a shock.

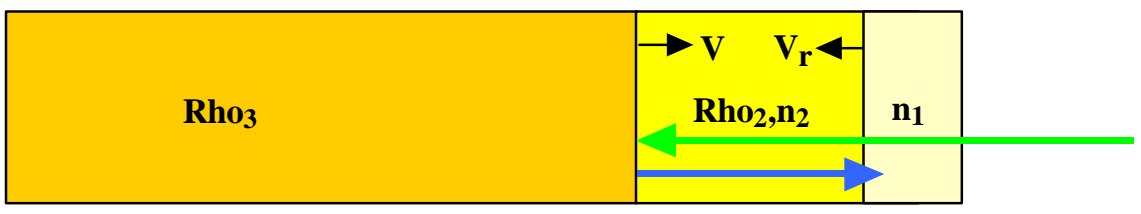

Figure 17. Same as above after the leading shock reaches the free surface. All velocities are in the lab frame.

After the leading shock reaches the end, there is a rarefaction going backwards with a speed of magnitude Vr. Now the shift from the downstream reflection is proportional to

$$
\mathrm{n}_{2} *\left(\mathrm{~V}+\mathrm{V}_{\mathrm{r}}\right)-\mathrm{V}_{\mathrm{r}} * \mathrm{n} 1=\mathrm{n}_{2} *(\mathrm{~V}-\mathrm{U})+\mathrm{n}_{1} * \mathrm{U}+\mathrm{V}_{\mathrm{r}} *\left(\mathrm{n}_{2}-\mathrm{n}_{1}\right)+\mathrm{U} *\left(\mathrm{n}_{2}-\mathrm{n}_{1}\right)
$$

Figure 17 assumes that shocks in the $\mathrm{CsCl}$ solution follow shocks in the aluminum. Then the apparent frequency changes by $\left(\mathrm{V}_{\mathrm{r}}+\mathrm{U}\right) *\left(\mathrm{n}_{2}-\mathrm{n}_{1}\right)$, which in most circumstances will be a positive shift It appears in the actual record that the unknown fringe does change in apparent velocity at this time. We have use this simple one-dimensional hydrodynamic analysis because the actual record indicates that the unknown fringe changes abruptly (for about 200 nsec) just as the leading shock reaches the end of the aluminum block. Since the velocity of the leading shock at 5.16 usec is about 5.51 $\mathrm{mm} / \mathrm{isec}$, we can use the Hugoniot data to determine the density behind this leading shock, and then use the simple estimate for the new index of refraction, $\mathrm{n}_{2}$ by using the simple model that $\mathrm{n}-1$ is proportional to compression. The result of this analysis is that the apparent velocity of $2.0 \mathrm{~mm} / \mathrm{isec}$ arises from an actual velocity near $2.2 \mathrm{~mm} / \mathbf{1} \mathrm{sec}$. This is close to the particle velocity in $\mathrm{CsCl}$ solution expected behind the leading shock.

Light only partially reflects from the leading shock, and most of it traverses deeper into the $\mathrm{CsCl}$ solution to possibly reflect from second shocks or from large enough scattering centers moving at a particle velocity.

Perhaps bubbles from rarefactions are the source of this unknown fringe. If this occurred promptly, it should start near 2 ìsec, where the side rarefaction reaches the axis, but it does not. Our mystery fringe starts at 3.6 ìsec. It may take that long to make scattering objects large enough to back-scatter light. 
In order to resolve this, we will carry out another experiment in the same geometry with the $\mathrm{CsCl}$ solution replaced by silica to see if the fringe still appears. It is very important to know if and when the probe itself is the cause of fringes that are not inherent in the driving material (aluminum in this case).

Many other experiments in aluminum were carried out. After taking the data shown in figure 14, we improved our technique to reduce gaps between the PTFE tubing and the driving material. The two records taken below used this method and the much improved smoothness of the records is very evident, compared to the records of figures 11 or 14 .

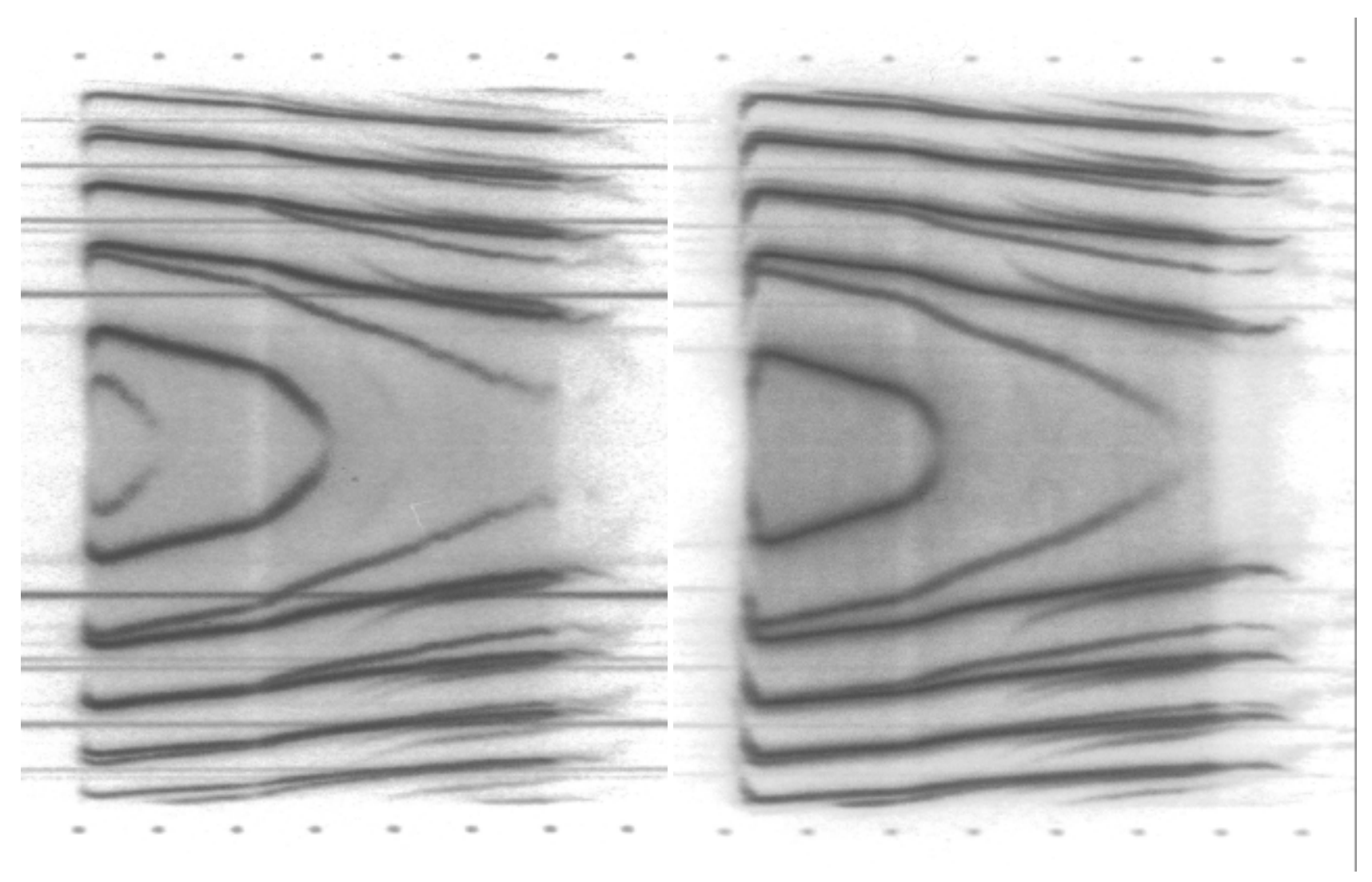

Figure 18. Shock decay in aluminum cylinder.

Figure 19. Shock decay in aluminum block.

The rarefaction from the sides of the aluminum shows up as the change in slope near 2.2 ìsec, where a band of lower exposure occurs also. The end of each record is different than that of figure 14, because these two used an O-ring seal at the late-time end of the aluminum samples which were $50 \mathrm{~mm}$ long. In order to more easily model the shock waves in a hydrodynamic code, we made one of the samples (shown in figure 18) a cylinder $25.4 \mathrm{~mm}$ diameter and $50 \mathrm{~mm}$ long. The other, shown in figure 16, was an aluminum block $25.4 \mathrm{~mm}$ wide and $50 \mathrm{~mm}$ long.

\section{SHOCK DECAY IN PMMA, PCTFE AND PTFE}

In order to determine the range of velocities that our probes can cover, we created decaying shocks in three plastic rectangular blocks each $25.4 \mathrm{~mm}$ wide and $50 \mathrm{~mm}$ long with the $1.6 \mathrm{~mm}$ diameter probes with the results shown below, all with 1 ìsec markers. The velocity in PMMA peaks at $5.23 \mathrm{~mm} / \mathrm{usec}$ and decays to $3.11 \mathrm{~mm} / \mathrm{usec}$ and coasts at this speed for the last $20 \mathrm{~mm}$ of motion, for reasons unknown to us. Shocks in PMMA are reported as low as $2.33 \mathrm{~mm} / \mathrm{usec}$. The PCTFE (poly-chloro-tetra-fluoro-ethylene) velocity ranges from 4.39 to $2.07 \mathrm{~mm} / \mathrm{isec}$. The PTFE block has velocities from $4.46 \mathrm{~mm} / \mathrm{usec}$ down to $1.56 \mathrm{~mm} / \mathrm{usec}$, close to sound speed (1.46) in the $\mathrm{CsCl}$ solution. 


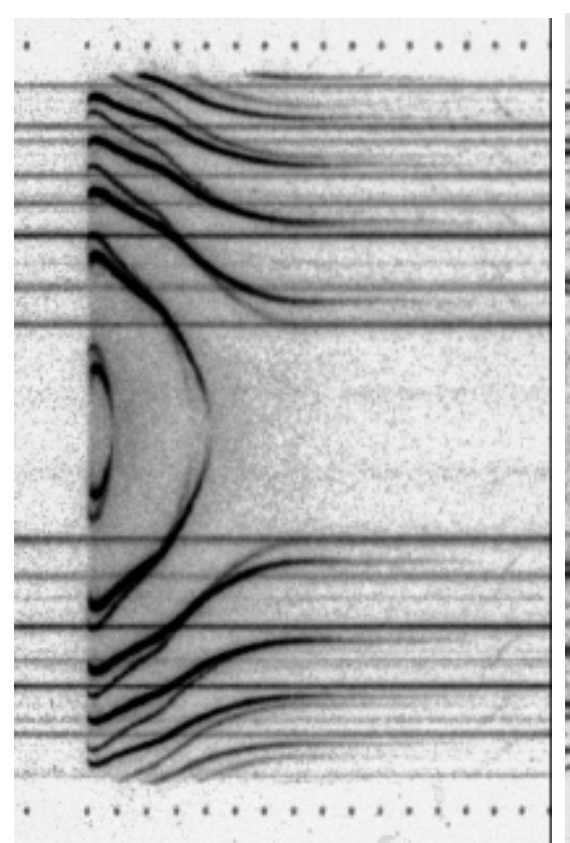

Figure 20. Shock decay in PMMA

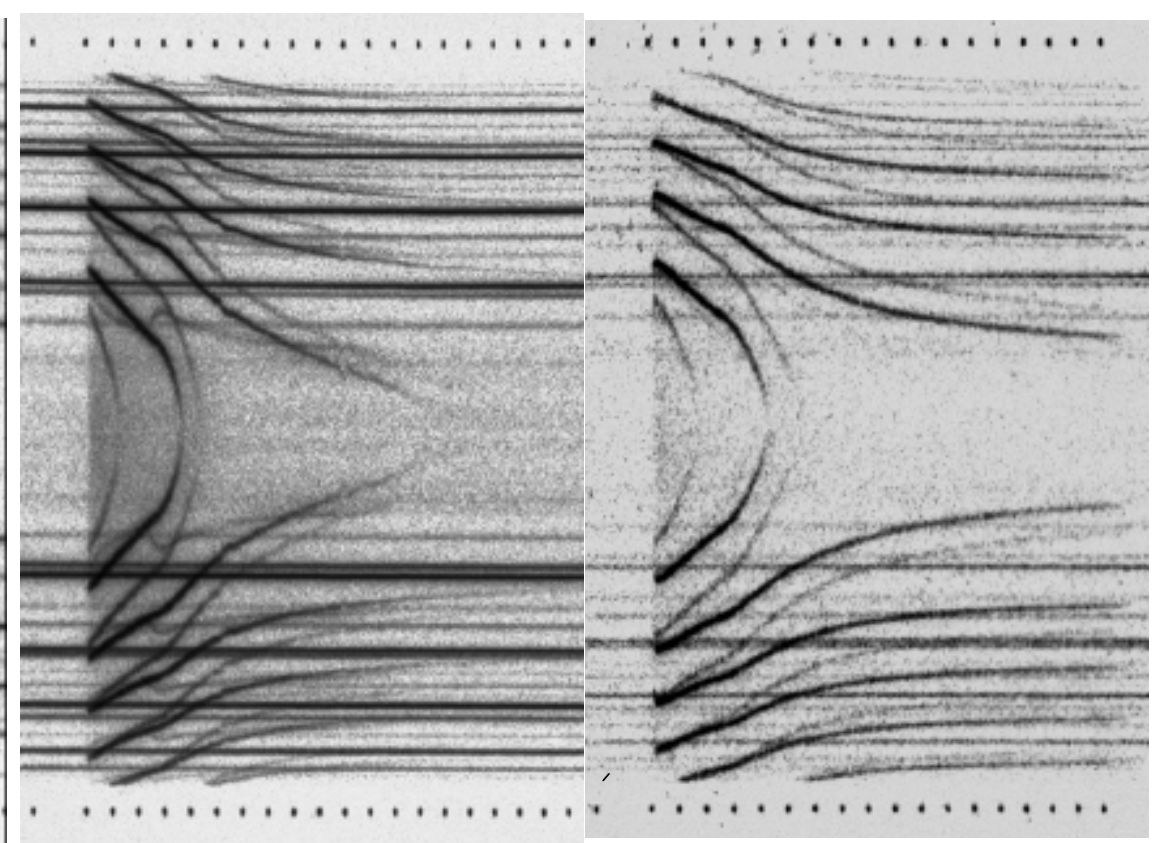

Figure 21. Shock decay in PCTFE
Figure 22. Shock decay in PTFE

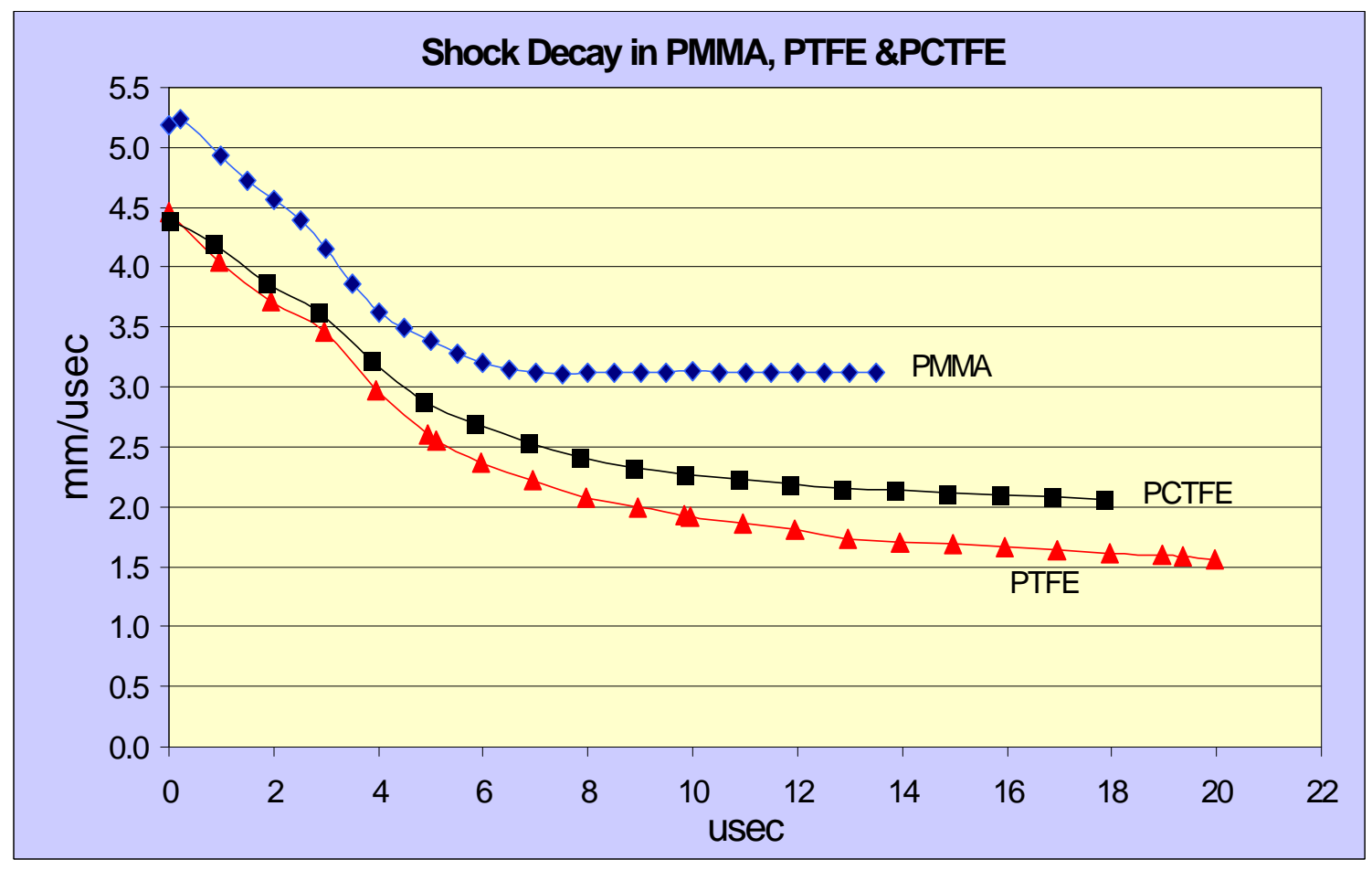

Figure 23. Shock decay in three plastic blocks 
These records used an different filler between the PTFE tubing and the plastic block material. This fills the gaps much better than glue and results in reliable, smooth velocity records. Many more experiments are planned to more fully characterize these and other probes. Important issues are the time response under various environments and assuring that different probes results in the same answer for the shock velocity.

The shoulder that appears at 5 ìsec in figure 22 is due to an intentionally introduced hydrodynamic perturbation in order to start learning how to make sharp position fiducials along the fiber axis. Several methods of making these fiducials are being tested. They will be very useful in determining where in the metal that a fringe is located if it is behind the leading shock wave. If one had existed in the aluminum record of figure 14, then the origin of the mystery fringe might be clarified by its location in space within the aluminum. Also, having distance fiducials will be a cross check on velocities where double cavity fringes are not made or are not bright enough. Figure 22 for PTFE also shows another mystery fringe, this time starting at the same time as the main (and presumably leading) shock wave. Unfortunately, there are no visible referee fringes for this weak pattern, so the apparent velocity cannot be determined uniquely.

We need to fully test our probes for response time, accuracy, and reproducibility, and to learn if any fringes can be made by the probes themselves which are not in the driving material to be measured. Also, we need to learn how thin the probes can be made and still survive normal 3-D hydronamic inhomogeneities within the driving material. Other issues are perturbations caused by probe mass, and making of position markers.

We believe that these probes and others to follow will provide tools for a new branch of shock-wave physics inside materials. We have seen velocities from 1.6 to $6.7 \mathrm{~mm} / \mathrm{usec}$ recorded, and expect them to work above 6.7. More than one shock wave can be recorded, and records may indicate the speed of a rarefaction wave in double shock experiments.

\section{REFERENCES}

1. D. R. Goosman, "Formulas for Fabry-Perot velocimeter performance using both stripe and multifrequency techniques", Appl. Opt. 30 (27), 3907-3923 (1991).

2. D. R. Goosman, G. Avara, L. Steinmetz, C. Lai and S. Perry, "Manybeam velocimeter for fast surfaces", SPIE proceedings on the $22^{\text {nd }}$ Int. Congress on High Speed Photography and Photonics, 2869, 1070-1079 (1996).

3. Willard Hemsing, private communication

4. C. Souers, private communication

5. D. R. Goosman, George Avara, James Wade, and Anthony Rivera, "Optical filters to exclude non-Doppler-shifted light in fast velocimetry",. SPIE proceedings on the $25^{\text {nd }}$ Int. Congress on High Speed Photography and Photonics, 4948, 152-159 (2002).

Work performed under the auspices of the U.S. Department of Energy by Lawrence Livermore National Laboratory under Contract W-7405-Eng-48. 